\title{
Socioeconomic inequalities and mortality among disability pensioners in Norway - a population-based cohort study
}

\author{
Sturla Gjesdal ${ }^{1,2,3}$, John Gunnar Mæland ${ }^{1}$, Jan Hagberg ${ }^{3}$ and Kristina Alexanderson ${ }^{3}$ \\ 1) Section for Social Medicine, Department of Public Health and Primary Health Care, University of Bergen \\ 2) Health Economics, University of Bergen \\ 3) Personal Injury Prevention, Department of Clinical Neuroscience, Karolinska Institutet, Stockholm \\ Correspondence: \\ Sturla Gjesdal, Department of Public Health and Primary Health Care, University of Bergen, Kalfarveien 31, 5018 Bergen, Norway \\ Telephone: +4755586150 Telefax: +4755586130 e-mail: sturla.gjesdal@isf.uib.no
}

\begin{abstract}
Background: The study assessed the mortality related to disability pension (DP) status in Norway during 1990-96 and investigated whether socioeconomic factors explained the increased mortality. Methods: A $10 \%$ random sample of the Norwegian population aged 30-59 years, 73,420 women and 75,500 men, were followed-up with respect to death or emigration in 1990-96. DP-status, age, gender, educational level and mean income before inclusion were used as explanatory variables in Cox' regression analysis with death as endpoint. The analyses were stratified for gender and separately for persons who had obtained DP before 1985 (early) and in 1985-1989 (late). Results: The majority of persons with DP had only basic education and belonged to the lowest income level. Among the women $6.2 \%$ in the DP-group died during follow-up compared to $1.2 \%$ of those in the non-DP group. The corresponding percentages for men were $14.5 \%$ and $2.3 \%$. The age-adjusted hazard ratios (HRs) were 3.5 and 2.5 for women with early and late DP, and 4.3 and 3.3 among men. After adjustment for socioeconomic variables, the HRs were 2.9 and 2.2 for women, and 2.2 and 1.9 for men. Conclusions: Nearly half of the excess mortality related to DP-status was explained by low socioeconomic status among the men. Among women, HR related to DP was not significantly reduced after the adjustments for socioeconomic variables. These findings indicate a strong impact of the medical factors underlying the DP decision, especially among women, but also an important role of the socioeconomic factors related to DP status.
\end{abstract}

\section{INTRODUCTION}

Over the last decades an increasing proportion of the population in Western Europe has become recipients of permanent social insurance benefits on medical grounds, disability pension (DP) or similar arrangements (1). This development is an important research and sociopolitical challenge, and new ways of preventing work disability and of providing more effective rehabilitation services have been called for $(2,3)$.

Norway is seen as a special case, with DP particularly significant compared to other welfare arrangements such as unemployment benefits (4). All legally registered inhabitants aged 18-66 years with more than three years residence are eligible for DP. Claimants should be at least 50\% incapacitated for any gainful work as a result of disease, injury or handicap. All relevant medical treatment should have been attempted and claimants should also have received vocational rehabilitation. The pension is calculated on the basis of previous incomes, up to a certain level, based on "pension points" or "G".

The annual number of new disability pensioners in Norway has varied considerably over the last 25 years, possibly linked to business cycles or period effects (5).
The variations have been greatest for women. The period 1985-89 showed a high influx to DP (6). Since 1961, when the Norwegian DP programme was established, the health status of the population has generally improved, measured against traditional yardsticks such as perinatal mortality and life expectancy. The growth of the DP programme has therefore been explained as "camouflaged unemployment" (7) or as "medicalisation" of social problems (8). The ill-health of DP recipients and those on long-term sickness absence has been questioned.

However, even though life expectancy has generally increased, it has been extensively documented that there remain large gradients in subjective health, long-term illness and mortality in the West European welfare states, linked to socioeconomic inequalities (911 ), and these might in fact be increasing (12).

Within traditional epidemiology, mortality is regarded as a strong indicator of health status. Long-term sickness absence as a predictor of future mortality has therefore become a new focus in socio-medical research $(13,14)$. While women generally have a higher incidence of sickness absence, the mortality risk is higher among men following sickness absence, and perhaps even more than the general male/female 
gradient in premature mortality (15). The increased mortality after sickness absence is also linked to demographic and socioeconomic variables such as age and occupational grade $(13,14)$.

Several studies, using different kinds of samples, and data from different periods (the 1970s, '80s and '90s), have documented an increased mortality among disability pensioners (16-19). A Swedish populationbased study with mortality data from 1985-1996 found that the mortality among DP recipients was three times higher than that of the normal population. The relative mortality was highest among the youngest age groups, and slightly higher among men (20). Another recent study from Sweden studied mortality between 19802002, comprising 6,887 individuals who had participated in health surveys between 1980 and 1993. The standardised mortality rates among persons with DP were 2.8 among women and 3.4 among men. However, with the exception of young age when obtaining DP, no medical or socioeconomic baseline variables clearly predicted mortality among the DP recipients (21).

There are several possible explanations for an increased mortality among disability pensioners: firstly, the increased mortality can be a result of the disease that underlies the DP, or risk factors of the disease, such as smoking (22). However, most cases of DP are granted because of musculoskeletal or common psychiatric disorders, i.e. conditions that normally do not lead to death. Secondly, it has been shown that low socioeconomic status (SES) predicts the granting of a DP (23-25), and the increased mortality might be explained by low SES or by factors linked to low SES, before and after obtaining a DP. Finally, the social, psychological and economic consequences of being marginalised outside the labour market may contribute to the increased mortality, in the same way as early retirement $(26,27)$ and long-term unemployment $(28,29)$.

The aims of the present study were:

- To assess the all-cause mortality of men and women with DP in Norway compared to the mortality of the normal population of the same age and gender.

- To investigate whether socioeconomic variables predicted future death among men and women with DP, and to what extent these factors explained the increased mortality.

\section{METHODS}

\section{Participants, the KIRUT database}

A prospective population-based study was carried out using data from the research database KIRUT (clients in, around and out of the social insurance system and the labour market) established by Norwegian Social Science Data Services (NSD). The database contains anonymous data on a random $10 \%$ sample of the Norwegian population obtained by linking public registers: the employment register, the tax and income register, the education register and registers set up by the Natio- nal Insurance Services (NIS), such as the DP register. Generally, the KIRUT database lacks sociodemographic information related to many young individuals; for this reason it was decided to exclude persons below 30 years from the study. Persons aged 60 and above were also excluded, since they would reach 67 years (normal retirement age) during follow-up. At 1 January 1990, data on 78,266 women and 81,531 men aged 3059 years (individuals born between 1930 and 1959) were available in the KIRUT database.

\section{Measurements}

The demographic and socioeconomic variables age, sex, educational level in years, and mean income (based on "G") up until 1989 were obtained from the KIRUT database.

- The variable "educational level" was categorised as basic (7-9 years), lower middle (10 years), higher middle (11-12 years) and high (13 years + ). For persons born before 1950 (aged 40+ in 1989), basic schooling comprised 7 years. For persons born after 1950 the basic education was extended to 9 years.

- Mean income was measured as "mean G" before inclusion. "G" stands for Norwegian "grunnbeløp", or "basic amount", and is an indexed measure which in 2006 was NOK 62,800 (approximately EUR 7,850).

- For DP cases, the year of granting of the pension was also known.

- KIRUT included data on deaths and emigration between 1990 and 1996.

\section{Follow-up and statistical analysis}

The study included 73,442 women and 75,500 men aged 30-59 years with no missing variables, followed up from 1 January 1990 until 31 December 1996, i.e. seven years (84 months). Survival analysis was carried out using Cox proportional hazard analysis with (time to) death as the dependent variable. Cases were censored at emigration or end of follow-up.

All analyses were conducted separately for women and men, since the identification of possible gender differences was an important research question. In order to identify predictors of death, demographic, socioeconomic factors and DP status were used as explanatory variables. To assess whether the time period of the granting of DP affected subsequent mortality the DP cases were divided in two groups: "early", i.e. those who had obtained DP before 1 January 1985, and "late", those who were granted DP between 19851989. Table 1 shows the descriptive statistics of the study sample.

To assess the general effect of socioeconomic variables on mortality risk in Norway from 1990-1996, the Cox regression analyses were first carried out for men and women without using DP status as an independent variable (table 2). Secondly, the Cox regression was performed for men (table 3) and women (table 4) in four models with a special focus on DP status as a 
Table 1. Distribution (percentages) according to age, educational level, and mean income, measured as mean "G", among individuals without disability pension (DP) and two groups of disability pensioners: "early" DP obtained before 1985 and "late" 1985-1989. Data from the KIRUT database: a representative sample of Norwegian women and med aged 30-59. N=73,420 women and 75,500 men aged 30-59 years at baseline. "G" is an indexed measure of annual income. $1 \mathrm{G}$ in 2006: NOK 62,800 (7,850 Euro).

\begin{tabular}{|c|c|c|c|c|c|c|}
\hline \multirow[b]{2}{*}{ Variables } & \multicolumn{2}{|c|}{ No DP } & \multicolumn{2}{|c|}{ DP before 1985} & \multicolumn{2}{|c|}{ DP 1985-1989 } \\
\hline & $\begin{array}{c}\text { Women } \\
\mathrm{N}=66,836\end{array}$ & $\begin{array}{c}\text { Men } \\
\mathrm{N}=71,388\end{array}$ & $\begin{array}{c}\text { Women } \\
\mathrm{N}=3,437\end{array}$ & $\begin{array}{c}\text { Men } \\
\mathrm{N}=2,230\end{array}$ & $\begin{array}{c}\text { Women } \\
\mathrm{N}=3,147\end{array}$ & $\begin{array}{c}\text { Men } \\
\mathrm{N}=1,882\end{array}$ \\
\hline \multicolumn{7}{|c|}{ Age (years) } \\
\hline $30-34$ & 21.4 & 21.0 & 4.9 & 5.3 & 5.1 & 6.7 \\
\hline $35-39$ & 20.4 & 20.2 & 7.1 & 9.0 & 8.5 & 6.6 \\
\hline $40-44$ & 20.5 & 20.9 & 14.2 & 14.3 & 13.3 & 13.2 \\
\hline $45-49$ & 15.3 & 15.6 & 15.6 & 15.2 & 18.0 & 13.9 \\
\hline $50-54$ & 11.8 & 11.8 & 22.7 & 20.4 & 23.8 & 21.9 \\
\hline $55-59$ & 10.6 & 10.5 & 35.6 & 35.8 & 31.2 & 37.7 \\
\hline \multicolumn{7}{|c|}{ Education (years) } \\
\hline $7-9$ & 25.7 & 22.7 & 58.2 & 56.1 & 53.3 & 51.5 \\
\hline 10 & 38.8 & 22.8 & 32.0 & 25.4 & 33.6 & 25.2 \\
\hline $11-12$ & 13.9 & 29.0 & 5.8 & 14.7 & 7.1 & 17.0 \\
\hline $13+$ & 21.6 & 25.5 & 4.0 & 3.9 & 6.0 & 6.3 \\
\hline \multicolumn{7}{|c|}{ Mean income "G" } \\
\hline 0-0.99 & 28.7 & 4.4 & 88.0 & 89.0 & 68.2 & 57.8 \\
\hline $1-1.99$ & 18.0 & 3.9 & 6.5 & 4.4 & 15.9 & 15.0 \\
\hline $2-2.99$ & 16.6 & 5.7 & 3.6 & 3.5 & 10.5 & 12.7 \\
\hline $3-3.99$ & 17.2 & 13.6 & 1.3 & 1.4 & 4.1 & 9.2 \\
\hline $4-4.99$ & 11.1 & 21.1 & 0.3 & 0.8 & 1.1 & 3.1 \\
\hline $5-5.99$ & 5.1 & 18.4 & 0.2 & 0.6 & 0.3 & 1.5 \\
\hline $6+$ & 3.3 & 32.7 & 0.0 & 0.2 & 0.0 & 0.7 \\
\hline
\end{tabular}

predictor of mortality. The relative risk of death or hazard ratio (HR), with $95 \%$ confidence intervals, was identified for each variable. The variables were grouped and treated as categorical because of no obvious linearity. The analyses were performed using the statistical software SPSS version 13.0.

\section{RESULTS}

At baseline, 6,973 women (8.9\%) and 4,603 men (5.6\%) were receiving DP. At the end of 1996, 669 men in the DP group had died $(14.5 \%)$ compared to 1,746 deaths among the non-DP group (2.3\%). Among the women there were 421 deaths in the DP group $(6.2 \%)$ and 855 deaths in the non-DP group (1.2\%).

The socioeconomic variables were distributed very differently among cases with and without DP at baseline (table 1). Among persons on DP, 52-58\% had only basic education compared to $23-26 \%$ among those not on DP. Mean income was even more unequally distributed. The mean age of the non-DP group was 42.3 years, compared to 49.5 years in the DP group.

In the Cox models with education and income as explanatory variables, without including DP status as an independent variable, the socioeconomic variables significantly predicted mortality, but the effect of low income was much weaker among women (table 2).

Table 3 shows the results of the Cox regression for men in four models: compared to the non-DP group, the crude HR was 7.1 among men on DP granted before 1985 and 5.6 for those with DP obtained between 1985 and 1989. After adjustment for age, the HRs fell to 4.3 and 3.3 respectively. In the final model with DP status, age, educational level and mean income, the HRs were 2.2 for "early DP" and 1.9 for "late DP", with overlapping confidence intervals. The confidence intervals of the HRs related to DP status in models 2 and 3 were overlapping, and by far the largest drop in HR came when income was introduced in model 4.

Results from the same analyses of the female sample are shown in table 4 . Generally the results were similar compared to the men, but the crude HRs related to DP were lower (5.6 and 3.9), and the HRs ratios in the fully adjusted model were higher compared to the men (2.9 and 2.2). The confidence intervals of the HRs related to DP status in the three last models were also overlapping.

\section{DiscuSsion}

\section{Main findings}

The study confirmed findings from other countries regarding a strongly increased mortality among DP recipients compared to the non-retired population of the same age and gender.

The age-adjusted relative risk of death among persons with DP was highest for men with HRs between 
Table 2. Effect of income and education (adjusted for age) on mortality in Norway 1990-1996. Data from The Kirut database $\mathrm{N}=73,420$ women and 75,500 men aged 30-59 years at baseline. Hazard ratios (HR) with 95\% confidence intervals (CI). Income measured as mean number of "G". "G" is an indexed measure of annual income. $1 \mathrm{G}$ in 2006: NOK 62,800 (7,850 Euro).

\begin{tabular}{|c|c|c|c|c|c|c|c|c|}
\hline \multirow[b]{2}{*}{ Variables } & \multicolumn{4}{|c|}{ Women } & \multicolumn{4}{|c|}{ Men } \\
\hline & $\mathrm{N}$ & Deaths & HR & $95 \% \mathrm{CI}$ & $\mathrm{N}$ & Deaths & HR & $95 \% \mathrm{CI}$ \\
\hline \multicolumn{9}{|c|}{ Education, yrs } \\
\hline $13+$ & 14734 & 140 & 1.0 & & 18434 & 282 & 1.0 & \\
\hline $11-12$ & 9746 & 86 & 0.9 & $0.7-1.2$ & 21333 & 494 & 1.2 & $1.1-1.4$ \\
\hline 10 & 28098 & 140 & 1.2 & $1.0-1.5$ & 17317 & 496 & 1.3 & $1.1-1.5$ \\
\hline \multirow[t]{2}{*}{$7-9$} & 20869 & 535 & 1.4 & $1.2-1.8$ & 18438 & 864 & 1.4 & $1.2-1.7$ \\
\hline & \multicolumn{4}{|c|}{$\mathrm{P}<0.001$} & & & \multicolumn{2}{|c|}{$\mathrm{P}<0.001$} \\
\hline \multicolumn{9}{|c|}{ Pension points mean } \\
\hline $6+$ & 2226 & 26 & 1.0 & & 23389 & 378 & 1.0 & \\
\hline $5-5,99$ & 3419 & 49 & 1.2 & $0.7-1.9$ & 13184 & 263 & 1.2 & $1.0-1.4$ \\
\hline $4-4,99$ & 7461 & 75 & 0.8 & $0.5-1.2$ & 15161 & 316 & 1.1 & $1.0-1.3$ \\
\hline $3-3,99$ & 11646 & 132 & 0.8 & $0.5-1.3$ & 9933 & 305 & 1.6 & $1.4-1.9$ \\
\hline $2-2,99$ & 11586 & 144 & 0.9 & $0.6-1.4$ & 4423 & 172 & 2.1 & $1.7-2.5$ \\
\hline $1-1,99$ & 12758 & 158 & 0.8 & $0.6-1.3$ & 3198 & 127 & 2.1 & $1.7-2.6$ \\
\hline \multirow[t]{2}{*}{$0-0,99$} & 24351 & 600 & 1.5 & $1.0-2.3$ & 6234 & 575 & 4.0 & $3.5-4.7$ \\
\hline & \multicolumn{4}{|c|}{$\mathrm{P}<0.001$} & & & \multicolumn{2}{|c|}{$\mathrm{P}<0.001$} \\
\hline \multicolumn{9}{|c|}{ Age groups } \\
\hline $30-34$ & 14634 & 69 & 1.0 & & 15213 & 124 & 1.0 & \\
\hline $35-39$ & 14127 & 100 & 1.5 & $1.1-2.0$ & 14783 & 162 & 1.4 & $1.1-1.8$ \\
\hline $40-44$ & 14640 & 160 & 2.3 & $1.7-3.1$ & 15505 & 299 & 2.5 & $2.0-3.0$ \\
\hline $45-49$ & 11366 & 207 & 3.8 & $2.9-5.0$ & 11736 & 362 & 3.8 & $3.1-4.7$ \\
\hline $50-54$ & 9401 & 240 & 4.9 & $3.8-6.5$ & 9311 & 455 & 5.6 & $4.6-6.8$ \\
\hline \multirow[t]{2}{*}{$55-59$} & 9279 & 408 & 7.9 & $6.1-10.2$ & 8974 & 734 & 8.5 & $7.0-10.3$ \\
\hline & \multicolumn{4}{|c|}{$\mathrm{P}<0.001$} & & & \multicolumn{2}{|c|}{$\mathrm{P}<0.001$} \\
\hline
\end{tabular}

3.3 and 4.3 compared to women with HRs between 2.5 and 3.5. However, after adjustment for the socioeconomic variables, the HR related to DP was slightly higher among women than men, but with overlapping confidence intervals both for "early" and "late" cases.

For men there was a significant fall in the HRs of $49 \%$ and $42 \%$ between the age-adjusted HR and the HR in the fully adjusted model. For women the reductions were $17 \%$ and $12 \%$, and not statistically significant. This gender difference may be explained by a low total mortality among middle-aged women. In addition, the most important causes of death among young and middle aged men are closely linked to SES (heart disease, accidents and alcohol/drug-related deaths), whereas the main causes of death among women in these age groups are less affected by SES (i.e. cancer).

Among the women, there was no longer a significant difference in mortality between "early" and "late" DP cases after adjustment for socioeconomic variables. This could mean that the lower mortality among the "late" cases was largely a result of improvements in education and income levels among persons granted DP in 1985-1989. Among the men there was no significant difference in mortality between "early" and "late" cases.

\section{Methodological considerations}

This was a population-based prospective cohort study, based on a large random sample of Norwegians from all counties, aged 30-59 years. The sample size, 73,422 women and 75,500 men with complete baseline data in 1989, was very large compared to studies from other countries, except for the recent Östergotland study from Sweden (20). The follow-up was restricted to a definite time period, 1990-1996. It is important to be aware that the mortality pattern of the middle-aged population has changed substantially over recent decades, especially among men (the fall of the coronary heart disease epidemic). The results from this study are therefore not necessarily valid for the most recent decade, or for the periods before 1990. It is also possible that those who have received their DP after 1989, may differ from the cases studied here. Persons under 30 years of age were not included because of too many missing variables. Persons between 60 and 66 years were not included either, and thus the mortality after retirement due to old age was not assessed in this study.

\section{The validity of the SES indicators: years of education and mean income}

Socioeconomic inequalities are believed to influence the health and mortality of populations, but how to measure these is not always straightforward. There is an ongoing discussion on which aspects of SES are the most important: education, income or position in the labour market (30). In Norway these factors have been shown to predict mortality differently according to causes of death (31). 
Table 3. Results of Cox regression analysis for the male sample: Hazard ratios (HR) for death with $95 \%$ confidence intervals (CI) according to DP-status adjusted for socioeconomic variables in 4 models. $\mathrm{N}=75,522$ men aged 30-59 years 1.1.1990, followed-up until 31.12.1996.

\begin{tabular}{|c|c|c|c|c|c|c|c|c|c|c|}
\hline \multirow[b]{2}{*}{ Variables } & \multirow[b]{2}{*}{$\mathrm{N}$} & \multirow[b]{2}{*}{ Deaths } & \multicolumn{2}{|c|}{ Model 1} & \multicolumn{2}{|c|}{ Model 2} & \multicolumn{2}{|c|}{ Model 3} & \multicolumn{2}{|c|}{ Model 4} \\
\hline & & & $\mathrm{HR}$ & $95 \% \mathrm{CI}$ & HR & $95 \% \mathrm{CI}$ & $\mathrm{HR}$ & $95 \% \mathrm{CI}$ & $\mathrm{HR}$ & $95 \% \mathrm{Cl}$ \\
\hline \multicolumn{11}{|l|}{ DP status } \\
\hline No DP (Ref) & 71388 & 1585 & 1.0 & & 1.0 & & 1.0 & & 1.0 & \\
\hline DP obtained before 1985 & 2230 & 329 & 7.1 & $6.3-8.0$ & 4.3 & $3.8-4.9$ & 3.9 & $3.4-4.4$ & 2.2 & $1.8-2.6$ \\
\hline \multirow[t]{2}{*}{ DP obtained 1985-1989 } & 1882 & 222 & 5.6 & $4.9-6.5$ & 3.3 & $2.9-3.9$ & 3.0 & $2.6-3.5$ & 1.9 & $1.6-2.3$ \\
\hline & & & \multicolumn{2}{|c|}{$\mathrm{P}<0.001$} & \multicolumn{2}{|c|}{$\mathrm{P}<0.001$} & \multicolumn{2}{|c|}{$\mathrm{P}<0.001$} & \multicolumn{2}{|c|}{$\mathrm{P}<0.001$} \\
\hline 30-34 (Ref) & 15213 & 124 & & & 1.0 & & 1.0 & & 1.0 & \\
\hline $35-39$ & 14783 & 162 & & & 1.3 & $1.0-1.7$ & 1.3 & $1.0-1.7$ & 1.4 & $1.1-1.7$ \\
\hline $40-44$ & 15505 & 299 & & & 2.2 & $1.8-2.8$ & 2.2 & $1.8-2.7$ & 2.4 & $1.9-2.9$ \\
\hline $45-49$ & 11736 & 362 & & & 3.5 & $2.8-4.3$ & 3.4 & $2.8-4.2$ & 3.6 & $3.0-4.5$ \\
\hline $50-54$ & 9311 & 455 & & & 5.1 & $4.2-6.2$ & 4.8 & $4.0-5.9$ & 5.1 & $4.2-6.3$ \\
\hline \multirow[t]{2}{*}{$55-59$} & 8974 & 734 & & & 7.4 & $6.1-9.0$ & 7.0 & $5.8-8.5$ & 7.4 & $6.1-9.0$ \\
\hline & & & & & \multicolumn{2}{|c|}{$\mathrm{P}<0.001$} & \multicolumn{2}{|c|}{$\mathrm{P}<0.001$} & \multicolumn{2}{|c|}{$<0.001$} \\
\hline $13+($ Ref $)$ & 18434 & 282 & & & & & 1.0 & & 1.0 & \\
\hline $11-12$ & 21333 & 494 & & & & & 1.4 & $1.2-1.6$ & 1.2 & $1.1-1.4$ \\
\hline 10 & 17317 & 496 & & & & & 1.5 & $1.3-1.8$ & 1.3 & $1.1-1.5$ \\
\hline \multirow[t]{2}{*}{$7-9$} & 18438 & 864 & & & & & 1.7 & $1.5-2.0$ & 1.4 & $1.2-1.6$ \\
\hline & & & & & & & \multicolumn{2}{|c|}{$\mathrm{P}<0.001$} & \multicolumn{2}{|c|}{$\mathrm{P}<0.001$} \\
\hline Pension points mean & & & & & & & & & & \\
\hline 6+ (Ref) & 23389 & 378 & & & & & & & 1.0 & \\
\hline $5-5.99$ & 13184 & 263 & & & & & & & 1.2 & $1.0-1.4$ \\
\hline $4-4.99$ & 15161 & 316 & & & & & & & 1.2 & $1.0-1.3$ \\
\hline $3-3.99$ & 9933 & 305 & & & & & & & 1.6 & $1.3-1.8$ \\
\hline $2-2.99$ & 4423 & 172 & & & & & & & 1.9 & $1.6-2.3$ \\
\hline $1-1.99$ & 3198 & 127 & & & & & & & 1.8 & $1.5-2.2$ \\
\hline \multirow[t]{2}{*}{$0-0.99$} & 6234 & 575 & & & & & & & 2.5 & $2.1-3.0$ \\
\hline & & & & & & & & & \multicolumn{2}{|c|}{$\mathrm{P}<0.001$} \\
\hline
\end{tabular}

Table 4. Results of Cox regression analysis for the female sample: Hazard ratios (HR) for death with $95 \%$ confidence intervals (CI) according to DP-status adjusted for socioeconomic variables in 4 models. $\mathrm{N}=73,447$ women aged 30-59 years 1.1.1990, followed-up until 31.12.1996.

\begin{tabular}{|c|c|c|c|c|c|c|c|c|c|c|}
\hline \multirow[b]{2}{*}{ Variables } & \multirow[b]{2}{*}{$\mathrm{N}$} & \multirow[b]{2}{*}{ Deaths } & \multicolumn{2}{|c|}{ Model 1} & \multicolumn{2}{|c|}{ Model 2} & \multicolumn{2}{|c|}{ Model 3} & \multicolumn{2}{|c|}{ Model 4} \\
\hline & & & HR & $95 \% \mathrm{CI}$ & $\mathrm{HR}$ & $95 \% \mathrm{CI}$ & HR & $95 \% \mathrm{CI}$ & $\mathrm{HR}$ & $95 \% \mathrm{Cl}$ \\
\hline \multicolumn{11}{|l|}{ DP status } \\
\hline No DP (Ref) & 66836 & 810 & 1.0 & & 1.0 & & 1.0 & & 1.0 & \\
\hline DP obtained before 1985 & 3437 & 229 & 5.6 & $4.9-6.5$ & 3.5 & $3.0-4.1$ & 3.3 & $2.8-3.8$ & 2.9 & $2.4-3.4$ \\
\hline DP obtained 1985-1989 & 3147 & 145 & 3.9 & $3.2-4.6$ & 2.5 & $2.1-3.0$ & 2.4 & $2.0-2.8$ & 2.2 & $1.8-2.6$ \\
\hline $\cos 2 \cos 20$ & & & \multicolumn{2}{|c|}{$\mathrm{P}<0.001$} & \multicolumn{2}{|c|}{$\mathrm{P}<0.001$} & \multicolumn{2}{|c|}{$\mathrm{P}<0.001$} & \multicolumn{2}{|c|}{$\mathrm{P}<0.001$} \\
\hline 30-34 (Ref) & 14634 & 69 & & & 1.0 & & 1.0 & & 1.0 & \\
\hline $35-39$ & 14127 & 100 & & & 1.5 & $1.1-2.0$ & 1.4 & $1.0-1.9$ & 1.4 & $1.1-2.0$ \\
\hline $40-44$ & 14640 & 160 & & & 2.2 & $1.6-2.9$ & 2.1 & $1.6-2.7$ & 2.1 & $1.6-2.8$ \\
\hline $45-49$ & 11366 & 207 & & & 3.4 & $2.6-4.5$ & 3.2 & $2.4-4.2$ & 3.3 & $2.5-4.3$ \\
\hline $50-54$ & 9401 & 240 & & & 4.3 & $3.3-5.6$ & 3.9 & $3.0-5.2$ & 4.1 & $3.1-5.3$ \\
\hline \multirow{2}{*}{$55-59$} & 9279 & 408 & & & 6.7 & $5.1-8.7$ & 6.1 & $4.7-7.9$ & 6.2 & $4.7-8.0$ \\
\hline & & & & & \multicolumn{2}{|c|}{$\mathrm{P}<0.001$} & \multicolumn{2}{|c|}{$\mathrm{P}<0.001$} & \multicolumn{2}{|c|}{$\mathrm{P}<0.001$} \\
\hline $13+($ Ref $)$ & 14734 & 140 & & & & & 1.0 & & 1.0 & \\
\hline $11-12$ & 9746 & 86 & & & & & 0.9 & $0.7-1.2$ & 0.9 & $0.7-1.2$ \\
\hline 10 & 28098 & 140 & & & & & 1.2 & $1.0-1.5$ & 1.2 & $1.0-1.5$ \\
\hline \multirow[t]{2}{*}{$7-9$} & 20869 & 535 & & & & & 1.4 & $1.1-1.7$ & 1.4 & $1.1-1.7$ \\
\hline & & & & & & & \multicolumn{2}{|c|}{$\mathrm{P}<0.001$} & \multicolumn{2}{|c|}{$\mathrm{P}<0.001$} \\
\hline $\begin{array}{l}\text { Pension points mean } \\
6+(\text { Ref })\end{array}$ & 2226 & 26 & & & & & & & 1.0 & \\
\hline $5-5.99$ & 3419 & 49 & & & & & & & 1.2 & $0.7-1.9$ \\
\hline $4-4.99$ & 7461 & 75 & & & & & & & 0.8 & $0.5-1.2$ \\
\hline $3-3.99$ & 11646 & 132 & & & & & & & 0.8 & $0.5-1.3$ \\
\hline $2-2.99$ & 11586 & 144 & & & & & & & 0.8 & $0.5-1.3$ \\
\hline $1-1.99$ & 12758 & 158 & & & & & & & 0.8 & $0.5-1.2$ \\
\hline \multirow[t]{2}{*}{$0-0.99$} & 24351 & 600 & & & & & & & 1.1 & $0.7-1.7$ \\
\hline & & & & & & & & & \multicolumn{2}{|c|}{$\mathrm{P}=0.064$} \\
\hline
\end{tabular}


In the present study, low education (number of years) had a significant effect on mortality among both women and men on DP, even though the type of education was not specified. The cut-off point for the highest group (13 years) might not fully express the social differences, since a university degree requires at least 15 years. On the other hand, other studies have used a division of only two educational groups $(21,32)$.

Tables 3 and 4 show that mean income had a strong and linear effect on mortality among men with DP $(p<0.001)$, but less so among women $(p=0.064)$. The effect of low income on mortality was however present, although quite weak, in the total female population between 1990 and 1996. The use of mean income, based on pension points, might be misleading for women. Family income could have been an alternative, even though this measurement also has problems (31). Social class, for instance manual versus non-manual occupations, was not specified in the KIRUT database.

\section{Other sources of systematic bias?}

The KIRUT database includes data from public registers, and the quality therefore depends on these registers. NSD (Norwegian Social Science Data Services) has published a report on the quality of KIRUT (32), pointing to some problem areas largely relating to variables with frequent changes, such as sickness absence and unemployment benefits. On the other hand, other variables that are extracted from registers such as the tax register and disability pension register are very reliable because of their importance for payment of pensions and collection of taxes. In the present study $6.8 \%$ of the cases were excluded because of missing variables on education and $2.1 \%$ had no information on pension points. There is no reason to believe that this introduced significant bias into the study.

\section{Possible confounders}

The DP diagnosis and other health and lifestyle factors related to DP status are the most likely confounders.
Several hypotheses have been suggested to explain the increased mortality among persons on DP, in addition to low SES and material deprivation: unhealthy lifestyles such as smoking, a known risk factor for becoming a disability pensioner (22), and poor diet, psychosocial stress, social marginalisation, and reduced coping skills. In this study we had no information on these factors.

\section{Need for further studies}

The increased mortality among individuals on DP is probably multi-factorial. The mortality patterns may also differ in the period before this study and in the most recent decade. Future studies should include better health data. Information on causes of DP and causes of death, together with information on lifestyle factors, especially smoking habits, might give better insight into these complex causal mechanisms. At present the authors are conducting such studies in both Norway and Sweden.

\section{Conclusions}

This study showed that in 1990-1996 middle-aged disability pensioners in Norway had a 3-4 times higher mortality compared to the "normal population" of the same age and gender. Socioeconomic factors explained approximately half of the increased mortality among men with DP. The more modest effect of socioeconomic factors on mortality among women on DP may partly be a result of imperfect measures of the SES of the women. The findings indicate that the underlying condition leading to DP, and other sociomedical factors, are important in explaining mortality gradients, especially among women.

\section{ACKNOWLEDGEMENT}

The data were supplied by the Norwegian Social Science Data Services (NSD), but the analyses are the sole responsibility of the authors.

\section{REFERENCES}

1. Stattin M. Retirement on grounds of ill health. Occup Environ Med 2005; 62 (2): 135-40.

2. Henderson M, Glozier N, Holland Elliott K. Long term sickness absence. BMJ 2005; 330: 802-3.

3. Marin B, Prinz C, Queisser M. Transforming disability welfare policies. Towards work and equal opportunities. Vienna: Ashgate, 2004.

4. Gjesdal S. From Long-term sickness absence to disability pension. Studies on predictors of disability pension in Norway. Medical dissertation. Bergen: University of Bergen, 2003.

5. Gjesdal S, Lie RT, Maeland JG. Variations in the risk of disability pension in Norway 1970-99. A genderspecific age-period-cohort analysis. Scand J Public Health 2004; 32 (5): 340-8.

6. Claussen B. Restricting the influx of disability beneficiaries by means of law: experiences in Norway. Scand $J$ Soc Med 1998; 26 (1): 1-7.

7. Kolberg J. En empirisk utprøving av utstøtingsmodellen. In: Hatland A, ed. Trygd som fortjent. En antologi om trygd og velferdsstat. Oslo: Ad Notam, 1991. 
8. Sundby P. [Disability as a paradox of health]. Tidsskr Nor Lageforen 1994; 114 (18): 2093.

9. Mackenbach JP, Kunst AE, Cavelaars AE, Groenhof F, Geurts JJ. Socioeconomic inequalities in morbidity and mortality in Western Europe. The EU Working Group on Socioeconomic Inequalities in Health. Lancet 1997; 349: 1655-9.

10. Huisman M, Kunst AE, Bopp M, Borgan JK, Borrell C, Costa G, et al. Educational inequalities in causespecific mortality in middle-aged and older men and women in eight western European populations. Lancet 2005; 365: 493-500.

11. Lahelma E, Kivela K, Roos E, Tuominen T, Dahl E, Diderichsen F, et al. Analysing changes of health inequalities in the Nordic welfare states. Soc Sci Med 2002; 55 (4): 609-25.

12. Mackenbach JP, Bos V, Andersen O, Cardano M, Costa G, Harding S, et al. Widening socioeconomic inequalities in mortality in six Western European countries. Int J Epidemiol 2003; 32 (5): 830-7.

13. Kivimaki M, Head J, Ferrie JE, Shipley MJ, Vahtera J, Marmot MG. Sickness absence as a global measure of health: evidence from mortality in the Whitehall II prospective cohort study. BMJ 2003; 327: 364.

14. Vahtera J, Pentti J, Kivimaki M. Sickness absence as a predictor of mortality among male and female employees. J Epidemiol Community Health 2004; 58 (4): 321-6.

15. Gjesdal S, Haug K, Mæland JG, Ringdal PR, Alexanderson K. Mortality after long-term sickness absence. Submitted manuscript, 2007.

16. Baker D, Packard M, Rader AD, Reno V, Upp M. Mortality and early retirement. Soc Secur Bull 1982; 45 (12): 3-10.

17. Jeune B. Survival experience of semi-skilled disability pensioners in Denmark. Scand J Soc Med $1982 ; 10$ (3): 73-6.

18. Quaade T, Engholm G, Johansen AM, Moller H. Mortality in relation to early retirement in Denmark: a population-based study. Scand J Public Health 2002; 30 (3): 216-22.

19. McCoy JL, Iams HM, Armstrong T. The hazard of mortality among aging retired- and disabled-worker men: a comparative sociodemographic and health status analysis. Soc Secur Bull 1994; 57 (3): 76-87.

20. Karlsson N, Carstensen J, Gjesdal S, Alexanderson K. Mortality in relation to disability pension: findings from a 12-year prospective population based cohort study. Scand J Public Health (In press) 2007.

21. Wallman T, Wedel H, Johansson S, Rosengren A, Eriksson H, Welin L, et al. The prognosis for individuals on disability retirement. An 18-year mortality follow-up study of 6887 men and women sampled from the general population. BMC Public Health 2006; 6: 103.

22. Husemoen LL, Osler M, Godtfredsen NS, Prescott E. Smoking and subsequent risk of early retirement due to permanent disability. Eur J Public Health 2004; 14 (1): 86-92.

23. Gjesdal S, Ringdal PR, Haug K, Maeland JG. Predictors of disability pension in long-term sickness absence: results from a population-based and prospective study in Norway 1994-1999. Eur J Public Health $2004 ; 14$ (4): 398-405.

24. Krokstad S, Johnsen R, Westin S. Social determinants of disability pension: a 10-year follow-up of 62000 people in a Norwegian county population. Int J Epidemiol 2002; 31 (6): 1183-91.

25. Mansson NO, Rastam L, Eriksson KF, Israelsson B. Socioeconomic inequalities and disability pension in middle-aged men. Int J Epidemiol 1998; 27 (6): 1019-25.

26. Mein G, Martikainen P, Hemingway H, Stansfeld S, Marmot M. Is retirement good or bad for mental and physical health functioning? Whitehall II longitudinal study of civil servants. J Epidemiol Community Health 2003; 57 (1): 46-9.

27. Tsai SP, Wendt JK, Donnelly RP, de Jong G, Ahmed FS. Age at retirement and long term survival of an industrial population: prospective cohort study. BMJ 2005; 331: 995 doi: 10.1136/ bmj. 38586.448704.E0.

28. Morris JK, Cook DG, Shaper AG. Loss of employment and mortality. BMJ 1994; 308: 1135-9.

29. Martikainen PT. Unemployment and mortality among Finnish men, 1981-5. BMJ 1990; 301: 407-11.

30. Davey Smith G, Hart C, Hole D, MacKinnon P, Gillis C, Watt G, et al. Education and occupational social class: which is the more important indicator of mortality risk? J Epidemiol Community Health 1998; 52 (3): 153-60.

31. Næss Ø, Claussen B, Thelle D, Davey Smith G. Four indicators of socioeconomic position: relative ranking across causes of death. Scand J Pub Health 2005; 33: 215-21.

32. Avendano M, Kunst AE, Huisman M, Lenthe FV, Bopp M, Regidor E, et al. Socioeconomic status and ischaemic heart disease mortality in 10 western European populations during the 1990s. Heart 2006; 92 (4): 461-7.

33. Kiberg D. Kvalitetskontroll av KIRUT-databasen. Norsk samfunnsvitenskapelig datatjeneste NSD notat nr. 4/1995. 